\title{
Status of selenium and correlation with blood GSH-Px in goats and their kids in organic breeding fed with different levels of organic selenium
}

\author{
Zvonko Antunović ${ }^{1}$, Tomislav Klapec², Suzana Ćavar³, Marcela Šperanda', Valentina \\ Pavić $^{4}$, Josip Novoselec ${ }^{1}$ and Željka Klir ${ }^{1}$ \\ ${ }^{1}$ Faculty of Agriculture, University of J. J. Strossmayer, Osijek, Croatia, ${ }^{2}$ Faculty of Food Technology, Croatia, ${ }^{3}$ Institute \\ of Public Health for Osijek-Baranya County, Osijek, Croatia, ${ }^{4}$ Department of Biology, University of J. J. Strossmayer, \\ Osijek, Croatia
}

\begin{abstract}
The aim of this research was to determine how the supplement of organic selenium in the diet at different concentrations reflects on the content of blood Se and GSH-Px activity and their correlation in goats and their kids in organic breeding. The study included 24 Alpine goat breeds during lactation and their kids. Goats were divided into three groups depending on dietary treatments. Goats were fed with the cereals mixture $1 \mathrm{~kg} / \mathrm{per}$ day in control group (C). Organic selenium supplied as selenised yeast in the first experimental group (E-I) $0.015 \%$ and in the second experimental group (E-II) $0.030 \%$ in cereals mixture. The addition of organic selenium significantly $(P<0.01)$ increased blood Se of goats and kids in $\mathrm{E}-\mathrm{I}$ and $\mathrm{E}-\mathrm{II}$ groups in relation to $C$ group and higher $(P<0.05)$ in $E-I I$ in comparison with the $E-I$ group. Concentrations of Se followed by GSH-Px activity, and were higher in the El and E-II groups in comparison with $C$ group. In the blood of suckling kids has determined higher $(P<0.01)$ GSH-Px activity in E-I and E-II groups in relation to C group. It was also determined higher GSH-Px in the blood of kids E-II group compared to the El group. Significant correlations was found between Se levels and GSH-Px activity in goats and kids, but were significant only in the goats of E-II group. The results obtained concentration of Se and GSH-Px in the blood goats and kids showed the validity of adding prganic selenium into food in organic breeding.
\end{abstract}

Keywords: goats, selenium, GSH-Px, organic selenium, blood, organic breeding

Abbreviations: C: control group, E: experiment group, GSH-Px: glutathione peroxidase

Archiv Tierzucht 56 (2013) 16, 169-177

doi: 10.7482/0003-9438-56-016

Corresponding author:

Zvonko Antunović; email: zantunovic@pfos.hr

Faculty of Agriculture in Osijek, University of J. J. Strossmayer in Osijek, Petra Svačića 1 d, 31000 Osijek, Croatia

C) 2013 by the authors; licensee Leibniz Institute for Farm Animal Biology (FBN), Dummerstorf, Germany.

This is an Open Access article distributed under the terms and conditions of the Creative Commons Attribution 3.0 License (http://creativecommons.org/licenses/by/3.0/).
Received: 21 February 2012 Accepted: 9 January 2013 Online: 1 March 2013 


\section{Introduction}

Studying the concentration of selenium in foods of animal origin is very important for the supply of human population to these essential microelements. The concentration of selenium in the animal organism is dependent on its intake with food (Surai 2006). Selenium is necessary for growth and fertility in animals and for prevention of variety of disease conditions (Kolodziej \& Jacyno 2005, Balicka-Ramisz et al. 2006, Gabryszuk et al. 2009, Marai et al. 2009). The bases of a meal in the feeding of ruminants, including goats are voluminous feed $(95 \%)$, while only $5 \%$ are concentrated feed. Most of the voluminous feeds used in the feeding of small ruminants are produce on poorer quality soils, which are often high humidity and acidity, and that prevents plants to adopt quality of selenium from the soil, even if it is in the soil in sufficient quantities. In the world there are endemic areas where lack of selenium in the soil causes a lack of selenium in plants grown on these soils (Gupta \& Gupta 2000, Antunović et al. 2010). Therefore, in many countries in the diet must add selenium. In recent years various studies are done with the addition of organic selenium in the food of small ruminants in different quantities (Kopić et al. 2007, Antunović et al. 2009b, Misurova et al. 2009a, Pavlata et al. 2011a, b). It was determined that organic selenium has better bioavailability and utilization in the body (Daniels 1996, Wolfram 1999, Pavlata et al. 2011a) and less excretion thus reducing environmental pollution. This is very important because in organic breeding are recommended the use of organic selenium in areas with selenium deficiency in the soil (Govasmark et al. 2005, Schlemmer et al. 2008, Steen et al. 2008). Selenium is an essential part of the enzyme glutathione peroxidase (GSH-Px) and plays an significance role in the intracellular a specific immune defence (Dercksen et al. 2007). Adequate methods for monitoring the supply of body selenium are related to the determination of its content in the blood and products supplemented animals and activity of GSH-Px in blood (Pavlata et al. 2011a, Antunović et al. 2009a, 2008, Lyons et al. 2007). Thomson et al. (2004) concluded that plasma or serum selenium reflects short-term status of selenium, erythrocyte selenium reflects longer-term status and hair or nail selenium reflect long-term selenium status in organism. Gerloff (1992) concluded that activity of GSH-Px can be indicator of long-term supplementation of organism with selenium, while determination blood selenium content indicator the short-term variation in the levels of this microelement. The aim of this investigation is to determine how the addition of organic selenium in the diet at different concentrations reflects on the content of selenium and GSH-Px in the blood of goats and their kids and their correlation to organic breeding.

\section{Material and methods}

\section{Animals, locations of investigation and diets}

The study included 24 Alpine goat breeds during lactation and their kids during the winter season. Goats were divided into three groups depending on dietary treatments and held by the »Regulation on organic production of animal products« (Ministry of Agriculture and Forestry of Croatia 2002). Goats were an average age of 4 years, healthy in third lactation, with one kid in the litter. Research began immediately after kidding and lasted 60 days. Goats were fed with the following cereals mixture: wheat, barley, corn and wheat bran (12\% crude 
protein, $10 \mathrm{MJ}$ NEL/kg) $1 \mathrm{~kg} /$ per day and meadow hay (11\% crude protein, $4.7 \mathrm{MJ} \mathrm{NEL} / \mathrm{kg}$ ) ad libitum. Organic selenium supplied as selenised yeast (Sel-Plex, Alltech Inc., Nicholasville, KE, USA). In the first experimental group (E-I) the Sel-Plex was added in cereals mixture $(0.015 \%)$ and in the second experimental group (E-II) the Sel-Plex (0.030\%). Beside milk, kids fed mentioned meal for goats at will. The content of selenium in feed of goats and kids is shown in Table 1.

Table 1

Selenium contents in goats' and kids' meals depending about nutrition treatments

\begin{tabular}{|c|c|c|c|}
\hline \multirow[t]{2}{*}{ Groups } & \multicolumn{3}{|c|}{ Selenium content } \\
\hline & Cereal mixture, mg/kg & Milk, $\mu \mathrm{g} / \mathrm{L}$ & Meadow hay, mg/kg \\
\hline Control (C) & 0.060 & 7.39 & 0.0035 \\
\hline Experiment I (E-I) & 0.075 & 10.57 & 0.0035 \\
\hline Experiment II (E-II) & 0.090 & 22.18 & 0.0035 \\
\hline
\end{tabular}

\section{Sampling and analyses}

Blood was collected from the jugular vein $(10 \mathrm{ml})$ into serum vacutainer tubes (Venoject, Sterile Terumo Europe, Leuven, Belgium) and ethylenediamine tetra-acetic acid (EDTA) after morning feeding on the 60th day of lactation. At the same time were taken blood samples from their kids. The EDTA tubes were inverted several times to ensure adequate mixing of the blood with anticoagulant. Blood serum was separated by centrifugation $(10 \mathrm{~min})$ at speeds of $3000 \mathrm{rpm}$. Concentrations of selenium in cereal mixture, meadow hay and goat milk were microwave assisted acid digested using concentrated nitric, perchloric and chloric acids (high pure) according to the method for Microwave Sample Preparation-MARS 5 (CEM, Matthews, NC, USA) in order to total the sample decomposition. Determination of selenium content was done by Continuous Hydride Generation Atomic Absorption method on PerkinElmer 2380 MHS-10 (PerkinElmer Inc., Waltham, MA, USA). Serum for determination of selenium was diluted (1+4) with $0.2 \%$ solution of Triton X-100 (Merck KGaA, Darmstadt, Germany). The concentration of total selenium in serum of goats and kids was determined by atomic absorption spectrometry, graphite technique on the apparatus AAnalyst 800/ Zeeman (PerkinElmer Inc., Waltham, MA, USA) with the addition of Pd and $\mathrm{Mg}\left(\mathrm{NO}_{3}\right)_{2}$ and matrix modifier (Pizent et al. 1999). The concentration was determined by standard addition method. Accuracy of the method was checked by determining the reference serum sample (Seronorm, Trace Elements in Serum, Sero AS, Billingstad, Norway). GSH-Px was determined in whole blood of goat and their kids with commercial »Ransel« kit (Randox Laboratories Ltd, London, UK). Method for determination of GSH-Px was based on catalytic oxidation of glutathione by cumen hidroxi peroxide, and for reading was used a Jenway 6305 UV/VIS spectrophotometer (Bibby Scientific Ltd, Staffordshire, UK).

\section{Statistical analysis}

The results were statistically evaluated by using LSD test in Statistica 8 (StatSoft, Inc. Tulsa, OK, USA). Differences were considered as significant at the level of 0.05 or less. The means 
and theirs standard deviation, min and max values as well as standard errors were also calculated. Pearson's correlation method and regression equation were used to assess the relation between blood concentration of selenium and GSH-Px activity in goat and their kids in Statistica 8.

\section{Results and discussion}

Analysing the Table 2 it is visible that the addition of organic selenium significantly increased selenium content in the blood of goats and their kids who are consumed mixture with the addition of Se in comparison to the control group. Activity of GSH-Px was also followed selenium concentrations and was significantly higher in the $\mathrm{E}$ groups than in the $\mathrm{C}$ group. It was also determined significantly higher $(P<0.05)$ Se concentration and GSH-Px activity in the blood of goat E-Il group compared to the E-I group. In the blood of suckling kids has determined significantly higher $(P<0.01) \mathrm{GSH}-\mathrm{Px}$ activity in both $\mathrm{E}$ groups compared to $\mathrm{C}$ group. It was also determined significantly higher $(P<0.05) \mathrm{GSH}-\mathrm{Px}$ in the blood of kids $\mathrm{E}-\mathrm{II}$ group compared to the E-I group.

Table 2

Blood selenium contents and activities of GSH-Px in goats and kids with different nutrition tretmans

\begin{tabular}{lcccccc}
\hline Values & \multicolumn{2}{c}{ Control } & \multicolumn{2}{c}{ Groups } \\
& Goat & Kid & Goat & Kid & Goriment I & Kid \\
\hline Selenium, $\mu \mathrm{g} / \mathrm{L}:$ & & & & & & \\
$\quad$ Mean & $36.18^{\mathrm{A}}$ & $19.17^{\mathrm{A}}$ & $72.30^{\mathrm{Ba}}$ & $35.87^{\mathrm{Ba}}$ & $82.15^{\mathrm{Bb}}$ & $44.20^{\mathrm{Bb}}$ \\
Standard deviation & 17.12 & 5.28 & 6.18 & 7.73 & 7.84 & 6.74 \\
Max & 70.00 & 28.56 & 80.94 & 44.00 & 93.82 & 54.30 \\
Min & 18.09 & 14.06 & 65.64 & 21.02 & 72.55 & 32.00 \\
Standard error & 6.05 & 1.87 & 2.18 & 2.73 & 2.77 & 2.38 \\
GSH-Px, $\mu$ kat/L: & & & & & & \\
Mean & $76.37^{\text {Aa }}$ & $52.58^{\mathrm{A}}$ & $146.17^{\mathrm{Ab}}$ & $108.25^{\text {Ba }}$ & $318.21^{\mathrm{B}}$ & $128.47^{\mathrm{Bb}}$ \\
Standard deviation & 38.53 & 13.06 & 39.48 & 15.57 & 66.41 & 19.10 \\
Max & 143.71 & 69.54 & 212.68 & 128.33 & 393.75 & 100.18 \\
Min & 20.12 & 34.15 & 97.72 & 90.00 & 218.43 & 158.56 \\
Standard error & 13.62 & 4.62 & 13.95 & 5.51 & 23.48 & 6.75 \\
\hline
\end{tabular}

Mean with different superscript letters differ significantly: ${ }^{\mathrm{a}, \mathrm{b}} P<0.05, \quad \mathrm{~A}, \mathrm{~B} P<0.01$

Similar conclusions have obtained Pavlata et al. (2011a, b) and Misurova et al. (2009a), although the concentrations of selenium and GSH-Px activities in these research were higher. The higher concentration of selenium in blood after application of organically form selenium (selenomethionine) results from directly incorporated into tissue proteins instead of methionine (Shrauzer 2003). Increased selenium concentrations in goats milk, blood and plasma as well as GSH-Px activity in whole blood of goats' food with organic selenium determined Khaled \& Illek (1999). Although placental transfer of selenium is more effective from the transport of selenium in milk (Pavlata et al. 2003), it is considered that the concentration of selenium and GSH-Px in the blood of goats after birth, is about $60 \%$ of maternal concentrations (Misurova et al. 2009b). In our investigation selenium contents in 
goat milk (from 7.39 in control group to $22.18 \mu \mathrm{g} / \mathrm{L}$ in E-Il group; Table 1) were slightly lower in comparison by results (from 23.31 to $31.26 \mu \mathrm{g} / \mathrm{L}$ ) in investigation by Petrera et al. (2009) and with results (from 9.2 to $31.2 \mu \mathrm{g} / \mathrm{L}$ ) in investigation by Rodriguez et al. (2002) and similar with results Pechova et al. (2008). Petrera et al. (2009) with the addition of selenium yeast in food of goats are determine significantly increased selenium levels and increased GSH-Px, but without significance. The main problem in using GSH-Px activity as attest for selenium assessment is related to variability of results between different laboratories. This is associated with differences in methodologies, samples storage, transport of samples and other (Surai 2006). In the $C$ group of goats and kids it is visible lack of selenium in the blood, which is connected with a reduced concentration in the diet (Table 1). Castillo et al. (2001) were determined influence of nutritional factors on the blood GSH-Px values in Assaf ovine breed. The limit value of deficiency in whole blood is $80 \mu \mathrm{g} / \mathrm{L}$ (Bickardt et al. 1999) and in serum $30 \mu \mathrm{g} / \mathrm{L}$ (Puls 1994). In Table 3 and Graphs 1, 2, 3, 4, 5 and 6 are shown the correlation and regression equation and curve between the concentration of blood selenium and GSH-Px of goats and their kids depending on the dietary treatments.

Table 3

Correlation and regression equation between blood selenium and GSH-Px activity in blood of goats and their kids

\begin{tabular}{|c|c|c|c|c|c|c|c|}
\hline \multirow[t]{2}{*}{ Correlation } & \multirow[t]{2}{*}{ Groups } & \multicolumn{2}{|c|}{ Control } & \multicolumn{2}{|c|}{$\begin{array}{l}\text { Selenium } \\
\text { Experiment I }\end{array}$} & \multicolumn{2}{|c|}{ Experiment II } \\
\hline & & Goats & Kids & Goats & Kids & Goats & Kids \\
\hline \multirow[t]{3}{*}{ GSH-Px } & C & $0.65(P>0.05)$ & $0.59(P>0.05)$ & - & - & - & - \\
\hline & E-I & - & - & $0.57(P>0.05)$ & $0.63(P>0.05)$ & - & - \\
\hline & $\mathrm{E}-\mathrm{II}$ & - & - & - & - & $0.77(P<0.05)$ & $0.66(P>0.05)$ \\
\hline \multicolumn{2}{|c|}{ Regression equation } & \multicolumn{2}{|c|}{ Goats } & \multicolumn{4}{|c|}{ Kids } \\
\hline \multicolumn{2}{|l|}{$\mathrm{Cl}$} & \multicolumn{3}{|c|}{ GSH-Px=23.239+1.4688 $\times \mathrm{Se}$} & \multicolumn{3}{|c|}{ GSH-Px=24.573+1.4609 $\times \mathrm{Se}$} \\
\hline \multicolumn{2}{|l|}{ E-I } & \multicolumn{3}{|c|}{$\mathrm{GSH}-\mathrm{Px}=-115.5+3.6185 \times \mathrm{Se}$} & \multicolumn{3}{|c|}{$\mathrm{GSH}-\mathrm{Px}=63.067+1.2594 \times \mathrm{Se}$} \\
\hline \multicolumn{2}{|l|}{$\mathrm{E}-\mathrm{II}$} & \multicolumn{3}{|c|}{$\mathrm{GSH}-\mathrm{Px}=-213.9+6.4770 \times \mathrm{Se}$} & \multicolumn{3}{|c|}{$\mathrm{GSH}-\mathrm{Px}=45.350+1.8807 \times \mathrm{Se}$} \\
\hline
\end{tabular}

Mean with different superscript letters differ significantly: a,b $P<0.05, P>0.05-\mathrm{ns}$

It is visible that high correlations were determined between these two parameters in goats, but were significant only in the E-II group. In the kids were also determined a high correlation between selenium and GSH-Px in the blood, but with no significant difference $(P>0.05)$. Mentioned points to relationship of these two indicators, although insignificant. The above shows the calculated regression equations and regression curves. In the research Pavlata et al. (2011b) were determined significant correlations $(r=0.72 ; P<0.01)$ between the concentration of selenium in whole blood and GSH-Px in the blood of goats. In the blood of kids were determined significantly high correlation $(\mathrm{r}=0.93 ; P<0.01)$ between serum selenium and GSH-Px in whole blood of growing kids (Pavlata et al. 2005), as well as the results Misurova et al. (2009b) which have in kids found a strong significant correlation $(r=0.64 ; P<0.01)$ between selenium concentration and GSH-Px. 




Se, $\mu \mathrm{g} / \mathrm{L}$
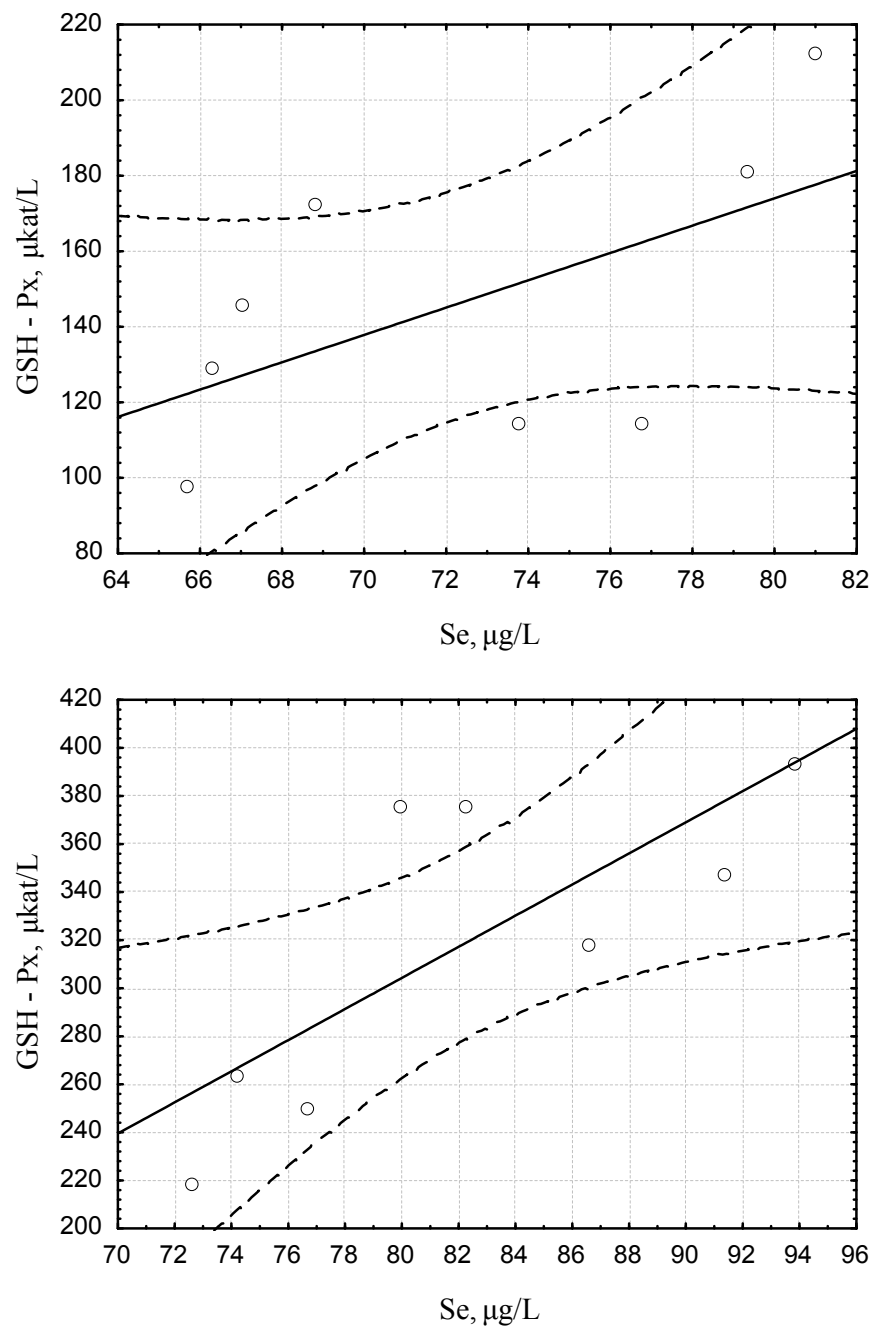

Figure 1, 2 and 3

Regression curve for blood concentration of selenium and GSH-Px in goats from C group, E-I group and E-II group 


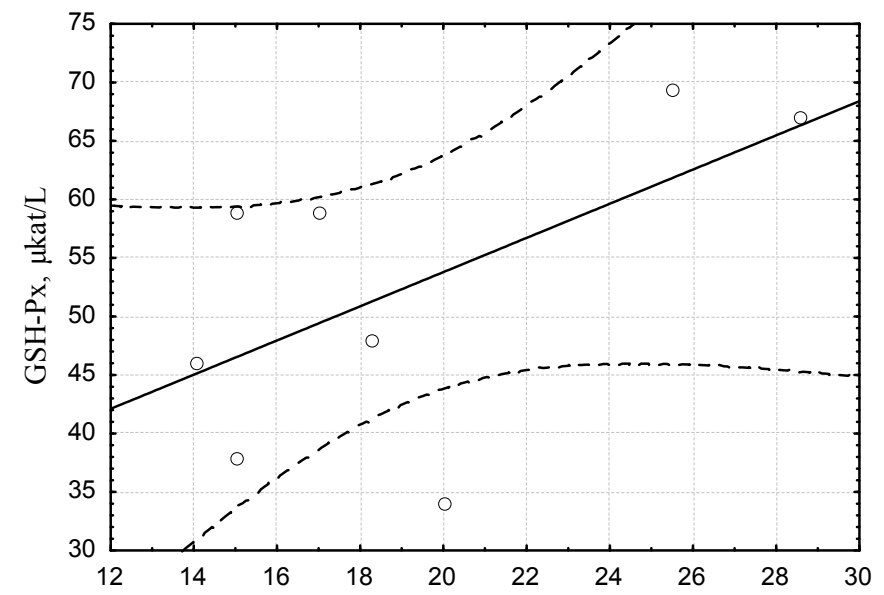

Se, $\mu \mathrm{g} / \mathrm{L}$

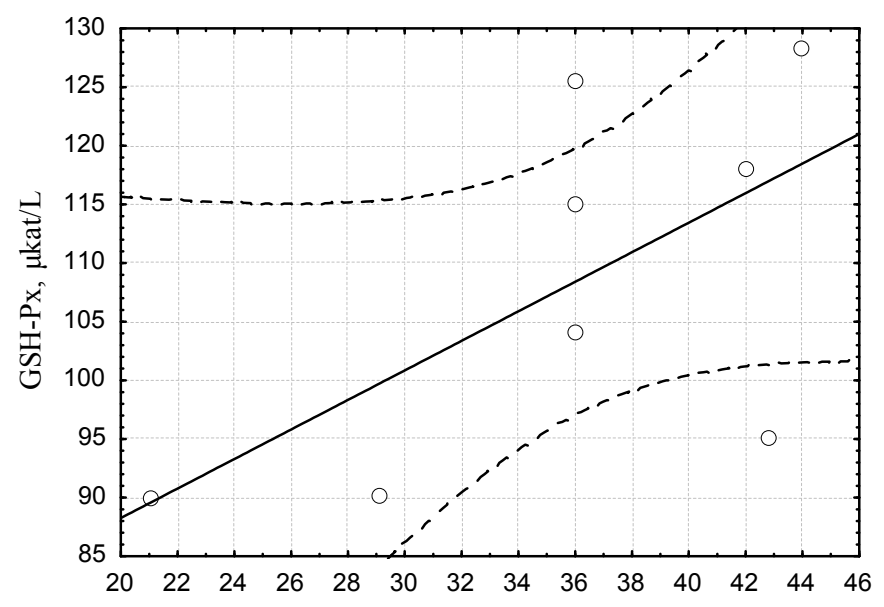

$\mathrm{Se}, \mu \mathrm{g} / \mathrm{L}$

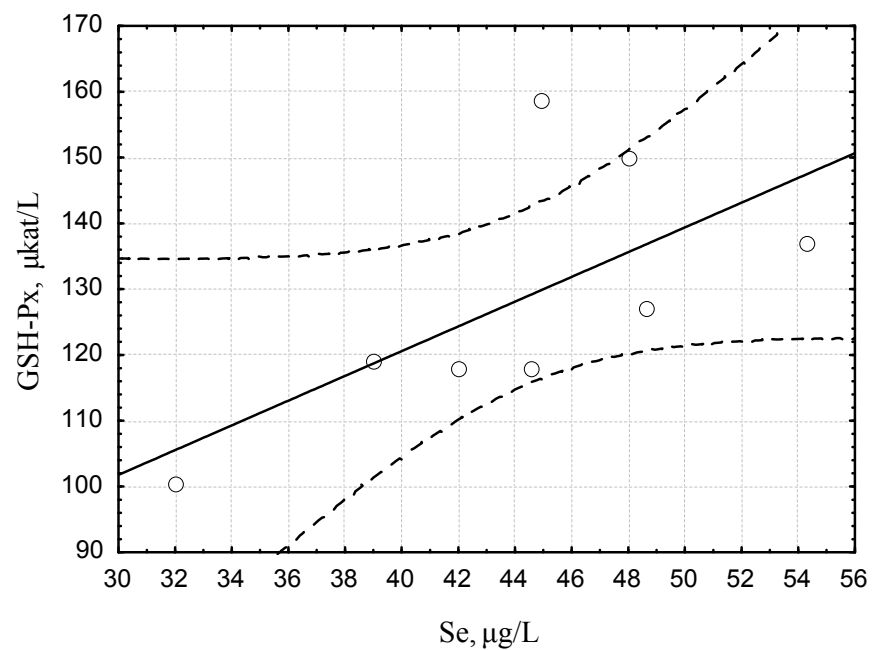

Figure 4, 5 and 6

Regression curve for blood concentration of selenium and GSH-Px in kids from C group, E-I group and E-II group 
In conclusion, the results obtained concentration of selenium and GSH-Px in the blood goats and their kids showed the validity of adding organic selenium into food in organic breeding.

\section{Acknowledgements}

This study part of a research project 2011-10-23 financed by the Ministry of Agriculture of the Republic of Croatia.

\section{References}

Antunović Z, Kopić B, Šperanda M, Steiner Z, Novoselec J (2008) [Influence of selenium on lambs productive traits and concentration of thyroid hormones.] Krmiva 50, 191-196 [in Croatian]

Antunović Z, Marić I, Matanić I, Senčić $Đ$, Šperanda M, Novoselec J (2009a) [Blood enzymes and thyroid hormones activity in assessment of selenium supply in sheep.] Krmiva 51, 131-137 [in Croatian]

Antunović Z, Novoselec J, Klapec T, Čavar S, Mioč B, Šperanda M (2009b) Influence of different selenium sources on performance, blood and meat selenium content of fattening lambs. Ital J Anim Sci 8 (Suppl.), 163-165

Antunović Z, Steiner ZD, Vegara M, Šperanda M, Steiner ZV, Novoselec J (2010) Concentration of selenium in soil, pasture, blood and wool of sheep. Acta Vet (Beograd) 60, 263-271

Balicka-Ramisz A, Pilarczyk B, Ramisz A, Wieczorek M (2006) Effects of selenium administration on blood serum Se content and on selected reproductive characteristics of sheep. Arch Tierz 49, 176-180

Bickhardt K, Ganter M, Sallmann P, Fuhrmann H (1999) Investigations on manifestations of vitamin E and selenium deficiency in sheep and goats. Dtsch Tierärztl Wochenschr 106, 242-247

Castillo C, Hernández J, Lopez-Alonso M, Miranda M, Benedito JL (2001) A Different Point of View of Glutathione Peroxidase: its Relationship to the Metabolic Changes Associated with Nutritional Management in Assaf ovine breed. Arch Tierz 44, 305-312

Daniels LA (1996) Selenium Metabolism and Bioavailability. Biol Trace Elem Res 54, 185-199

Dercksen DP, Countte GH, Hazebroek MK, Arts W, Van Rijn T (2007) [Selenium requirements of dairy goats.] Tijdschr Diergeneeskd 132, 468-471 [in Dutch]

Gabryszuk M, Horbanczuk K, Klewiec J (2009) Rearing, fattening performance and slaughter indicators of lambs after selenium, zinc and vitamin E supplementation. Arch Tierz 52, 309-320

Gerloff BJ (1992) Effect of selenium supplementation on dairy cattle. J Anim Sci 70, 3934-3940

Govasmark E, Steen A, Strom T, Hansen S, Singh BR, Bernhoft A (2005) Status of selenium and vitamin E on Norwegian organic sheep and dairy cattle farms. Acta Agric Scand A 55, 40-46

Gupta UC, Gupta SC (2000) Selenium in soils and crops, its deficiencies in livestock and humans: Implications for management. Commun Soil Sci Plant Anal 31 Special Issue, 1791-1807

Khaled NF, Illek J (1999) Influence of dietary supplementation of selenium-enriched yeast on selenium status of dairy goats. In: Anke M et al. (eds) Mengen- und Spurenelemente. 19. Arbeitstagung. Jena, Germany, 244-251

Kolodziej A, Jacyno E (2005) Effect of selenium and vitamin E supplementation on reproductive performance of young boars. Arch Tierz 48, 68-75

Kopić B, Antunović Z, Šperanda M, Steiner Z, Matanić I, Rajković V (2007) [Organic selenium application in lambs nutrition.] Krmiva 49, 73-78 [in Croatian]

Lyons MP, Papazyan TT, Surai PF (2007) Selenium in Food Chain and Animal Nutrition: Lessons from Nature Review. Asian-Aust J Anim Sci 20, 1135-1155

Marai IFM, El-Darawany AHA, Abou-Fandoud Ismail ES, Abdel-Hafez MAM (2009) Reproductive and physiological traits of Egyptian Suffolk rams as affected by selenium dietary supplementation and housing heat radiation effects during winter of the sub-tropical environment of Egypt. Arch Tierz 52, 402-409 
Ministry of Agriculture and Forestry of Croatia (2002) Regulation on organic production of animal products, Zagreb, Croatia

Misurova L, Pavlata L, Pechova A, Dvorak R (2009a) Effect of long-term peroral supplementation with sodium selenite and selenium lactate-protein complex on selenium status in goats and their kids. Vet Med 54, 324-332

Misurova L, Pavlata L, Pechova A, Dvorak R (2009b) Selenium metabolism in goats - maternal transfer of selenium to newborn kids. Vet Med 54, 125-130

Pavlata L, Misurova L, Pechova A, Dvorak R (2011a) The effect of inorganic and organically bound forms of selenium on glutahthione peroxidase activity in the blood of goats. Vet Med 56, 75-81

Pavlata L, Chomat M, Pechova A, Misurova L, Dvorak R (2011b) Impact of long-term supplementation of zinc and selenium on their content in blood and hair in goats. Vet Med 56, 63-74

Pavlata L, Slosarkova S, Fleischer P, Pechova A (2005) Effects of increased iodine supply on the selenium status of kids. Vet Med 50, 186-194

Pavlata L, Prášek J, Podhorsky A, Pechová A, Haloun T (2003) Selenium Metabolism in Cattle: Maternal Transfer of Selenium to Newborn Calves at Different Selenium Concentrations in Dams. Acta Vet Brno 72, 639-646

Pechová A, Janštová B, Mišurová L, Dračková M, Vorlová L, Pavlata L (2008) Impact of Supplementation of Various Selenium Forms in Goats on Quality and Composition of Milk, Cheese and Yogurth. Acta Vet Brno 77, 407-414

Petrera F, Calamari L, Bertin G (2009) Effect of either sodium selenite or Se-yeast supplementation on selenium status and milk characteristics in dairy goats. Small Rumin Res 82, 130-138

Pizent A, Jurasović J, Pavlović M, Telišman S (1999) Serum Copper, Zinc and Selenium Levels with Regard to Psychological Stress in Men. J Trace Elem Med Biol 13, 34-39

Puls R (1994) Mineral Levels in Animal Health: Diagnostic Data, 2nd ed., Sherpa Int., Clearbrook, B.C., Canada

Rodriguez Rodriguez EM, Sanz Alaejos M, Diaz Romeo C (2002) Mineral content in goat's milks. J Food Qual 25, 343-358

Schrauzer GN (2003) The nutritional significance, metabolism and toxicology of selenomethionine. Adv Food Nutr Res 47, 73-112

Schlemmer I, Reese S, Ebert U, Metzner M (2008) Case report of iodine deficiency in an organic dairy farm. V.C.O.T. $36,179-184$

Steen A, Strom T, Bernhoft A (2008) Organic selenium supplementation increased selenium concentrations in ewe and newborn lamb blood and in slaughter lamb meat compared to inorganic selenium supplementation. Acta Vet Scand 50:7

Surai PF (2006) Selenium in nutrition and health, Nottingham University Press

Thomson CD (2004) Assessment of requirements for selenium and adequacy of selenium status: a review. Eur J Clin Nutr 58, 391-402

Wolffram S (1999) Absorption and metabolism of selenium: differences between inorganic and organic sources. In: Lyons TP, Jacques KA (eds) Under the Microscope. Focal Points for the New Millenium. Biotechnology in the Feed Industry. Proceedings of Alltech's 15th Annual Symposium. Nottingham University Press, Nottingham, UK, 547-566 